\title{
KOMPETENSI LITERASI INFORMASI MAHASISWA (Studi Kasus di Universitas Sebelas Maret Surakarta)
}

\author{
Masriyatun \\ Universitas Sebelas Maret Surakarta (UNS) \\ masriyatun@yahoo.com
}

\begin{abstract}
Abstrak
Kompetensi literasi informasi pernah diteliti oleh Association of College \& Research Libraries Standards Committee dan hasilnya diakui oleh The Board of Directors of the Association of College and Research Libraries (ACRL). Literasi informasi telah menjadi sebuah program wajib di berbagai lembaga, khususnya perpustakaan. Jenis penelitian ini dengan menggunakan metode deskriptif kuantitatif. Jumlah populasi 220 dengan sampel 22. Teknik pengambilan sampel secara random sampling. Teknik pengumpulan data dengan observasi dan kuesioner. Adapun Teknik analisis dengan menggunakan SPSS 22. Tujuan penelitian ini untuk mengetahui komnpetenasi literasi informasi mahasiswa. Berdasarkan hasil pembahasan, hasil yang diketahui bahwa variable kompetenasi literasi informasi mahasiswa di UPT Perpustakaan UNS dikategorikan sedang yaitu sejumlah 14 orang atau $59,1 \%$.
\end{abstract}

Kata Kunci : Literasi Informasi, Perpsutakaan

\section{A. Pendahuluan}

UPT Perpustakaan UNS merupakan perpustakaan satusatunya yang ada di Universitas Sebelas Maret, karena mulai dari bulan Mei 2016 perpustakaan tingkat fakultas di jadikan satu ke 
perpustakaan tingkat universitas, jadi lebih tepatnya bahwa terjadi adanya sentralisasi perpustakaan. UPT Perpustakaan UNS buka dari hari Senin sd Sabtu dan mulai dari jam 07.30 pagi sampai dengan jam 21.00 malam. Dengan adanya hal tersebut, tidak heran bahwa kunjungan pemustaka datang dan pergi silih berganti, ada dari yang hanya datang mencari referensi bila tidak ditemukan yang dicari langsung pulang, ada yang membaca dengan mengerjakan tugas di tempat meja baca, ada yang hanya mencari setelah mendapatkan buku yang dicari langsung pulang, serta ada yang tidak membaca dan tidak pinjam buku namun chatingan serta mainan yutub sampai larut malah hanya karena dapat memanfaatkan wifi yang telah disediakan oleh perpustakaan.

Menurut pengamatan penulis, ada beberapa mahasiswa yang begitu datang di perpustakaan khususnya di koleksi local content mereka langsung datang di meja komputer yang telah disediakannya guna penelusuran informasi yang dibutuhkan oleh mahasiswa. Mereka datang langsung membuka catatan yang dibawanya untuk dicari di depan komputer (OPAC) yang disediakannya untuk segera melakukan penelusuran sesuai dengan kebutuhan informasi yang dibutuhkan. Setelah mencari tidak ditemukannya baru menghampiri petugas (pustakawan) bahwa informasi yang dicarinya kok tidak ada, sehingga baru meminta bantuan kepada pustakawan. Dari permintaan yang dilakukan oleh mahasiswa tersebut, baru pustakawan memberikan bantuan sesuai dari permintaannya, sebagai contoh untuk mencari judul buku dengan menunjukkan nomor klasifikasi, sedangkan program studi judul tersebut tidak diketahuinya sehingga akan menyulitkan bagi pemustaka maupun pustakawan dalam membantu untuk mendapatkannya. Apabila pustakawan menemui mahasiswa yang mengalami permasalahan tersebut, pustakawan berusaha membantu untuk menjelaskannya baik dari proses pencarian maupun menjelaskan keberadaan buku tersebut ada atau tidaknya. Dalam melakukan proses pencarian tidak jarang bahwa informasi yang dicari tidak diketemukan juga walaupun sudah pernah 
didampingi oleh pustakawan. Tidak ditemukakannya tersebut karena apa, apakah dia tidak bisa cara mengambil tema dari judul yang dicari, apakah tidak mengetahui nomor klasifikasinya, apakah tidak tahu judul tersebut masuk dalam program studi apa, tidak tahu alamat webnya, apalagi model penelusurannya dan sebagainya nah hal ini diperlukan adanya kemampuan dalam bidang literasi informasi. Dengan permasalahan tersebut, jadi penulis ingin mencoba mengkaji untuk mengetehui seberapa besar kompetensi literasi informasi mahasiswa tersebut di UPT Perpustakaan UNS.

\section{Tinjauan Pustaka}

Penelitian sebelumnya, Kompetensi lietrasi informasi mahasiswa (Studi pada Universitas Airlangga dan Universitas Negeri Surabaya)

Beberapa definisi literasi informasi yang dikembangkan oleh berbagai organisasi kepustakawanan internasional antara lain :

1. ACRL (Asociation of collage and research Libararies)

Literasi informasi adalah seperangkat keterampilan yang dibutuhkan seseorang untuk mengenali kapan informasi dibutuhkan seseorang serta ketrampilan untuk menelusur, mengevaluasi, dan menggunakan dengan efektif informasi yang dibutuhkan.

2. CILIP (Chartered Institute of Librray and Information Professionals)

Literasi informasi adalah mengetahui kapan dan mengapa informasi dibutuhkan, dimana ditemukan, dan bagaimana mengeavluasi, menggunakan dan mengkomunikasikan dengan perilaku yang beretika. (Perpustakaan Kemenkes RI, 2016 ; 4)

Dari dua definisi di atas, keterampilan inti literasi informasi yang bisa dirumuskan untuk dikuasai oleh pustakawan dan pemustaka adalah : 
1. Analisa Kebutuhan Informasi

2. Strategi Penelusuran

3. Pendayagunaan Informasi

4. Sintesa Informasi

5. Etika Profesi Bidang Informasi

Perpustakaan adalah institusi pengelola karya tulis, karya cetak dan atau karya rekam secara professional dengan sistem yang baku guna memenuhi kebutuhan pendidikan, penelitian, dan rekreasi pemustaka. (Permenkes RI no. 58 Tahun 2015 pasal 1 ayat 1 dalam Literasi Informasi Kemenkes RI, 2016))

\section{Metodologi Penelitian}

Jenis penelitian ini merupakan deskriptif dengan metode kuantitatif. Adapun penelitian ini mempunyai tujuan untuk mengetahui kemampuan literasi informasi mahasiswa di Universitas Sebelas Maret Surakarta. Data penelitian dengan menggunakan data primer. Teknik pengumpulan data dengan bentuk observasi dan kuesioner. Teknik pengambilan sampel dengan cara random sampling (mengambil secara acak) sebesar 10\% dari jumlah populasi, dimana populasi dalam penelitian ini sejumlah 220 mahasiswa yang datang di koleksi local content UPT Perpustakaan UNS. Sedangkan teknik pengolahan data dengan SPSS 22. Jadi sampel dalam penelitian ini sejumlah 22 orang mahasiswa. Dengan karakteristik responden sebagai berikut :

\begin{tabular}{|c|l|c|c|}
\hline No. & \multicolumn{1}{|c|}{ Nama } & Umur (Tahun) & Jenis Kelamin \\
\hline 1. & Cantika & 21 th & $\mathrm{P}$ \\
\hline 2. & Evelin & 22 th & $\mathrm{P}$ \\
\hline 3. & Zarah & 21 th & $\mathrm{P}$ \\
\hline 4. & Sumarni & 40 th & $\mathrm{P}$ \\
\hline 5. & Dyah Fitriana & $22 \mathrm{th}$ & $\mathrm{P}$ \\
\hline 6. & Novi & 43 th & $\mathrm{P}$ \\
\hline 7. & Ida & $21 \mathrm{th}$ & $\mathrm{P}$ \\
\hline 8. & Hesti & 20 th & $\mathrm{P}$ \\
\hline 9. & Ochian & & $\mathrm{L}$ \\
\hline
\end{tabular}




\begin{tabular}{|c|l|c|c|}
\hline 10. & Ariska Tri & 20 th & $\mathrm{P}$ \\
\hline 11. & Elga & 20 th & $\mathrm{P}$ \\
\hline 12. & Intania & 22 th & $\mathrm{P}$ \\
\hline 13. & Meilan & 22 th & $\mathrm{P}$ \\
\hline 14. & Hanafiah & 20 th & $\mathrm{P}$ \\
\hline 15. & Ratna & 21 th & $\mathrm{P}$ \\
\hline 16. & Rizka & 21 th & $\mathrm{P}$ \\
\hline 17. & Adipati & 21 th & $\mathrm{L}$ \\
\hline 19. & Sekar & 21 th & $\mathrm{P}$ \\
\hline & Vanessa & 21 th & $\mathrm{P}$ \\
\hline 18. & & 23 th & $\mathrm{P}$ \\
\hline 19. & Fransisca & 22 th & $\mathrm{P}$ \\
\hline 20. & Rio & $\mathrm{h}$ & $\mathrm{P}$ \\
\hline 21. & Reni & & \\
\hline 22. & Yeni & & \\
\hline
\end{tabular}

Sumber : Data Primer yang diolah.

\section{B. Pembahasan}

Dalam sebuah perguruan tinggi, kenapa literasi informasi dibutuhkan? Keterampilan literasi informasi sangat penting karena di era globalisasi kemajuan teknologi semakin berkembang. Kemajuan teknologi tersebut menyebabkan kelimpahruahan informasi. Sehingga dalam memenuhi kebutuhan informasi diperlukan adanya kemampuan dalam bidang literasi informasi. Dalam hal ini literasi informasi yang digunakan menurut ACRL.

Variabel kompetensi literasi informasi mahasiswa di Universitas Sebelas Maret Surakarta, diukur melalui 5 indikator yaitu : 1. Menentukan sifat dan cakupan informasi yang dibutuhkan; 2. Mengakases informasi yang dibutuhkan secara efektif dan efisien; 3. Mengevaluasi informasi dan sumber-sumber secara kritis; 4 . Menggunakan informasi untuk menyelesaikan tujuan tertentu; 5. Memahami aspek ekonomi, hukum dan sosial yang berkaitan dengan penggunaan informasi. Dalam variable ini dijelaskan ke dalam 16 pernyataan, seperti berikut ini : 


\section{Kompetensi Literasi Informasi Mahasiswa (Studi Kasus Pada Universitas Sebelas Maret Surakarta)}

\begin{tabular}{|c|c|}
\hline No. & Pernyataan \\
\hline \multirow[t]{5}{*}{ A. } & Menentukan sifat dan cakupan informasi yang dibutuhkan \\
\hline & Saya mampu mendefinsikan kebutuhan informasi \\
\hline & $\begin{array}{l}\text { Saya mampu mengidentifikasi beragam jenis dan format dari sumber - } \\
\text { sumber informasi yang potensial }\end{array}$ \\
\hline & $\begin{array}{l}\text { Saya mampu memper- timbangkan biaya dan mafaat dari pencarian } \\
\text { informasi yang dibutuhkan }\end{array}$ \\
\hline & $\begin{array}{l}\text { Saya mampu mengevaluasi kembali sifat dan cakupan informasi yang } \\
\text { dibutuhkan }\end{array}$ \\
\hline \multirow[t]{6}{*}{ B. } & Mengakases informasi yang dibutuhkan secara efektif dan efisien \\
\hline & $\begin{array}{l}\text { Saya mampu menyeleksi metode pencarian atau sistem temu kembali } \\
\text { informasi yang paling tepat untuk mencari informasi yang dibutuhkan }\end{array}$ \\
\hline & Membangun dan menerapkan strategi penelusuran yang efektif \\
\hline & $\begin{array}{l}\text { Saya mampu menemukan kembali informasi secara on-line atau secara } \\
\text { pribadi menggunakan beragam metode }\end{array}$ \\
\hline & Saya mampu mengubah strategi penelusuran jika perlu \\
\hline & $\begin{array}{l}\text { Saya mampu, mengutip, mencatat, dan mengolah informasi dan sumber- } \\
\text { sumbernya }\end{array}$ \\
\hline \multirow[t]{7}{*}{ C. } & Mengevaluasi informasi dan sumber- sumber secara kritis \\
\hline & $\begin{array}{l}\text { Saya mampu meringkas ide utama yang dapat dikutip dari informasi yang } \\
\text { terkumpul }\end{array}$ \\
\hline & $\begin{array}{l}\text { Saya mampu mengeluarkan dan menggunakan kriteria awal untuk } \\
\text { mengevaluasi informasi dan sumber- sumbernya }\end{array}$ \\
\hline & $\begin{array}{l}\text { Saya mampu mengumpulkan ide-ide utama untuk membangun konsep } \\
\text { baru }\end{array}$ \\
\hline & $\begin{array}{l}\text { Saya mampu membandingkan pengetahuan baru dengan pengetahuan } \\
\text { terdahulu untuk menentukan nilai tambahnya, kontradiksi atau } \\
\text { karakteristik unik lainnya dari informasi }\end{array}$ \\
\hline & $\begin{array}{l}\text { Saya mampu apakah pengetahuan baru memiliki dampak terhadap sistem } \\
\text { nilai seseorang dan menentukan cara untuk menyatukan perbedaan- } \\
\text { perbedaan }\end{array}$ \\
\hline & $\begin{array}{l}\text { Saya mampu membuktikan kebenaran dari pemahaman dan interpretasi } \\
\text { informasi melalui diskusi dengan individu lain, para ahli, dan / atau } \\
\text { praktisi }\end{array}$ \\
\hline \multirow[t]{3}{*}{$\mathrm{D}$} & Menggunakan informasi untuk menyelesaikan tujuan tertentu \\
\hline & $\begin{array}{l}\text { Saya mampu menggunakan informasi baru dan yang terdahulu untuk } \\
\text { perencanaan dan penciptaan hasil yang istimewa atau performa }\end{array}$ \\
\hline & Saya mampu merevisi proses pengembangan untuk hasil atau performa \\
\hline
\end{tabular}




\begin{tabular}{|l|l|}
\hline & $\begin{array}{l}\text { Saya mampu mengkomunikasikan hasil atau performa secara efektif } \\
\text { kepada orang lain }\end{array}$ \\
\hline E & $\begin{array}{l}\text { Memahami aspek ekonomi, hukum dan sosial yang berkaitan dengan } \\
\text { penggunaan informasi }\end{array}$ \\
\hline $\begin{array}{l}\text { Memahami isu-isu ekonomi, hukum dan aspek sosial ekonomi seputar } \\
\text { informasi dan teknologi informasi }\end{array}$ \\
\hline $\begin{array}{l}\text { Saya mampu mengikuti peraturan / hukum serta kebijakan institusi dan } \\
\text { etika yang berhubungan dengan akses dan penggunaan sumber-sumber } \\
\text { informasi }\end{array}$ \\
\hline $\begin{array}{l}\text { Saya mampu menghargai penggunaan sumber-sumber informasi dalam } \\
\text { mengkomunikasikan produk atau performasi }\end{array}$ \\
\hline
\end{tabular}

\section{Sumber : data kuesioner}

Sebelum mengetahui kategori variable kompetenasi literasi infomasi mahasiswa diperlukan intuk menghitung interval kelas terlebih dahulu dengan rumus sebagai berikut :

$$
\begin{aligned}
& \text { Nilai Tertinggi - Nilai Terendah } \\
& \text { Jumlah kelas } \\
& 109-69 \quad 40 \\
& \mathrm{I}= \\
& 5 \quad 5
\end{aligned}
$$

Sedangkan untuk mengetahui kategori variable kompetansi literasi informasi diukur melalui 5 kategori yaitu sangat tinggi, tinggi, sedang, rendah dan sangat rendah, seperti yang dijelaskan dalam tabel berikut ini :

TABEL II

Distribusi Frekuensi Variabel Kompetensi Literasi Informasi Mahasiswa

\begin{tabular}{|c|l|c|c|c|}
\hline No. & \multicolumn{1}{|c|}{ Kategori } & Nilai & Jumlah & $\begin{array}{c}\text { Prosentase } \\
(\%)\end{array}$ \\
\hline 1. & Sangat Tinggi & 101 & 1 & 4,5 \\
\hline 2. & Tinggi & $86-100$ & 7 & 31,9 \\
\hline 3. & Sedang & $78-85$ & 14 & 59,1 \\
\hline 4. & Rendah & $70-77$ & 0 & 0 \\
\hline 5. & Sangat Rendah & $<68$ & 1 & 4,5 \\
\hline & & & 22 & 100 \\
\hline
\end{tabular}

Sumber : Kuesioner indicator 1-5. Pernyataan 1 sd 21. 
Berdasarkan table di atas, dapat diketahui bahwa responden yang menyatakan sangat tinggi sejumlah 1 orang atau $4,5 \%$. Sedangkan yang menyatakan tinggi sejumlah 7 orang atau 31,9 $\%$ dan yang menyatakan sedang sejumlah 14 orang atau 59,1\%. Jadi dalam hal ini dapat disimpulkan bahwa rata-rata responden menyatakan sedang karena menempati pada nilai 78-85.

\section{Penutup}

Berdasarkan hasil pembahasan mengenai variable kompetensi literasi informasi mahasiswa di UPT Perpustakaan UNS, didapatkan hasil sebagai berikut yaitu yang menyatakan sangat tinggi sejumlah 1 orang atau $4,5 \%$. Sedangkan yang menyatakan tinggi sejumlah 7 orang atau $31,9 \%$ dan yang menyatakan sedang sejumlah 14 orang atau 59,1\%. Jadi dalam hal ini dapat disimpulkan variable kompetensi literasi informasi mahasiswa di UPT Perpustakaan UNS mempunyai kategori sedang. 


\section{DAFTAR PUSTAKA}

Dewi Puspitasari, Mutty Hariyati, 2016. Kompetensi Literasi Informasi Mahasiswa (Studi pada Universitas Airlangga dan Universitas Negeri Surabaya) dalam Prosiding Seminar Internasional "Transformasi peprustakaan sebagai Manajemen Data research untuk mendukung World class University" Surabaya, 25-26 April 2018.

Perpustakaan Kemenkes RI, 2016. Literasi Informasi Kemenkes RI, Biro Komunikasi dan Pelayanan Masyarakat, Jakarta Selatan.

Priyanto, Duwi (2014). SPSS 22 ; pengolah data terpraktid, Yogyakarta: Andi

Singarimbun, Masri; Effendi, Sofian. (1989). Metode Penelitian Survai. Jakarta: LP3ES. 
